\title{
The Effect of Positive Leadership on Organizational Citizenship Behavior based on Self-determination theory
}

\author{
Yunneng Fu, Rosmelisa Yusof*, Aizzat Hj. Mohd. Nasurdin \\ School of Management, Universiti Sains Malaysia, USM, Penang, 11800, Pulau Pinang, Malaysia \\ *Corresponding Author.
}

\begin{abstract}
Based on the theory of self-determination and the related literature of positive leadership, we explore the internal mechanism of the influence of positive leadership on organizational citizenship behavior, especially the mediating role of intrinsic motivation and the moderating role of right distance. Through the statistical test and analysis of 281 data in China, we use SPSS 23.0 and Mplus7.0 to test our research hypothesis. Consistent with our hypothesis, the results show that positive leadership can have a significant positive effect on intrinsic motivation. Positive leadership can have an indirect positive impact on organizational citizenship behavior partly through the transmission of intrinsic motivation. Power distance can weaken the positive effect of positive leadership on intrinsic motivation, that is, for employees with high power distance, the positive effect of positive leadership on intrinsic motivation is weaker, on the contrary, the positive effect of positive leadership on intrinsic motivation of employees with low power distance is stronger. Power distance can adjust the mediating effect of intrinsic motivation between positive leadership and organizational citizenship behavior, that is, the stronger the power distance of employees, the weaker the indirect relationship between positive leadership and organizational citizenship behavior through intrinsic motivation.
\end{abstract}

Keywords: Positive leadership, power distance, intrinsic motivation, organizational citizenship behavior, self-determination theory

\section{Introduction}

In the 21st century, one of the greatest changes in human history is China's economic rise and take-off, which makes a backward agricultural country become the second largest economic entity both domestic and overseas. As a result, Chinese enterprises have achieved transformation and rise, and the competition between industries and enterprises has become increasingly fierce. In addition to the continuous strengthening of core capabilities such as technology, service, organizational management and marketing, soft management, especially in stimulating the autonomy and enthusiasm of employees, has become the choice of more and more enterprises. More and more management researchers begin to focus on the advantages and positive characteristics of enterprises, rather than the problems and defects existing in enterprises. People's potential is unlimited, how to better motivate employees to improve organizational behavior and performance, has become the choice of more scholars. In this context, more and more researchers pay attention to OCB. Organizational citizenship behavior (OCB) is a kind of random individual behavior of employees, which has no direct or explicit connection with the formal reward system, but can effectively improve the organizational effectiveness as a whole. It's called casual because it's not a mandatory requirement in the role or the statement of work, but a personal choice, and even if it doesn't show up, it won't be punished. In other words, organizational citizenship behavior (OCB) is other helpful attitude and behavior to the organization. It is neither emphasized by the formal role nor required by the labor remuneration contract, but it is made up of many informal acts of mutual assistance. Although organizational citizenship behavior can not directly lead to the direct interests of individuals, it can bring benefits to groups or organizations [1].

How to stimulate the enthusiasm and initiative of employees, how to better develop the potential of employees, so that employees can carry out more behavior outside the role of the organization, in the research of organizational leadership, many scholars in the world have done research, such as the influence of transformational leadership on

ISSN: 0010-8189

(C) CONVERTER 2021

www.converter-magazine.info 
organizational citizenship behavior. This study shows that transformational leadership has a significant impact on the organizational citizenship behavior of subordinates. This predictive power mainly lies in that the boss's personalized care can effectively predict subordinates' altruistic behavior, sense of responsibility, civic virtue and polite behavior [2]. According the effect of empowering leadership on organizational citizenship behavior, many scholars have studied it. Empowering leadership means that leaders will share their power with their subordinates and improve their autonomy and sense of responsibility [3]. The impact of empowering leadership on individual creativity [4], team (e.g., team performance) [5] and organizational level (e.g., company performance) [6] have positive effects. However, from the perspective of positive organizational behavior, there are few research on the influence of positive leadership on OCB both domestic and overseas. In the current increasingly competitive environment, the requirements of enterprises for employees are not only to complete the tasks within the role, but also on the premise of completing the tasks within the scope of work responsibilities, OCB is very important behaviors to encourage workers to actively perform and make some out of role behaviors. Therefore, it is very important to study how positive leadership affects OCB.

Positive leadership is the most hot topics in current management studies [7]. Since the 1990s, under the comprehensive influence of the continuous development of positive organizational behavior, so the increasing attention paid to the role of leaders in improving employee cohesion, maintaining work initiative and improving organizational performance [8]. When the elements of positive psychology theory are applied to the field of leadership, it has formed the earliest state of positive leadership, and gradually developed into a new and effective way of leadership, which is more in line with the highly developed economy and society. The research on positive leadership can be traced back to the speech of Martin Seligman. The theme of the 1998 annual meeting of the American Psychological Association is "prevention: enhancing young people's strength, resilience and health" (American Psychological Association, 1998).The positive leadership style is newer than other leadership styles, which is based on such a thinking concept: when employees work in a positive environment, they will be happier and have higher work motivation. Therefore, leaders use positive strategies to influence employees and it is easier to achieve organizational goals. This conclusion is supported by a large amount of evidence in meta-analysis, which shows that positive emotions and positive organizational climate are related to the improvement of happiness, productivity and profitability [9]. In the aspect of empirical research, the researchers investigated 40 business departments of a large financial services company in the northeast of the United States. The results show that positive practice is related to financial performance, work atmosphere, employee turnover and organizational efficiency [10]. Positive leadership is mainly reflected in the focus on staff strength, positive attitude in the face of difficulties, and frequent praise of team members' performance, which has become the key to entrepreneurial success [11].

Because positive leadership is a new concept compared with other leadership styles, relevant research has only been developed in recent years, so it has not been found that scholars have studied the effect of positive leadership on OCB, but we can get some inspiration from the influence of other leadership types on OCB, Because of the close relationship between positive leadership and other leadership types, such as service leadership, transformational leadership and moral leadership. Authorized leadership has a positive correlation with organizational citizenship behavior, however, the analysis of the mechanism and boundary conditions of this process is limited; The authorized leadership will show a series of behaviors of sharing power, such as: let employees participate in the organization decision-making and let the employees complete the tasks independently. These behaviors can't directly promote the employees to show more OCB, especially considering the meaningful of OCB to improve the competitiveness and performance of the organization, the underlying mechanism needs to be further explored of positive leadership to influence the organizational citizenship behavior of employees [12][13].

What kind of psychological mechanism does positive leadership indirectly affect the organizational citizenship behavior of employee. Positive leadership is a psychological strategy to promote the positive mental health, significance and goals of team members [14]. Employees' attitude and behavior change is often related to their

ISSN: 0010-8189

(C) CONVERTER 2021

www.converter-magazine.info 
identification with leaders, and the identity leadership can come from transformational leadership style. When employees feel this style, they will not only accomplish the task of responsibility division, but also be more willing to take on other matters [15]. Transformational leaders often become the example of employees. Their own words and deeds and charm are an incentive for employees. Employees will choose challenging work more actively and actively give advice for the development of the organization [16]. Transformational leadership can promote organizational citizenship behavior of employees, because this leadership style is conducive to improving the working atmosphere, enhancing the motivation of employees and making employees voluntarily fulfill the goal of exceeding their own interests [17]. In consideration of that other closely associated leadership types of leadership can improve their autonomy and enthusiasm, trust in leaders, and improve the performance of employees, these can meet the basic mentally requirements of subordinates (relationship, competence and autonomy).

When a person has a stronger extrovert type, the higher the level of intrinsic motivation, and the experience of this type is more easily attracted by interesting and content-based work [18]. The spiritual needs of employees' self-satisfaction, achievement needs and competency are also one of the key factors that affect employees' intrinsic motivation. Employees who desire to succeed and have the competence to work will show higher intrinsic motivation level. These employees prefer to obtain the satisfaction of autonomy, belonging and competence in the work [19]. In addition, the working environment can also influence the intrinsic motivation, including the leadership style, working conditions, and organizational culture of the managers. The leadership style of managers, especially the support type and positive type, advocates the authorization and gives the employees a great degree of freedom will make the employees experience the fun and significance of the work more easily, and can also positively affect the intrinsic motivation level of the employees [20]. The working conditions provided by the organization to the employees and some characteristics of the organization itself will also affect the intrinsic motivation level of the employees. When the organization advocates the independence of the employees, creates an organization atmosphere of fair competition, provides timely work feedback, and meets the psychological needs of the employees' sense of belonging and competence, Employees will show stronger intrinsic motivation and more positive working attitude, and then show higher performance level [21].Therefore, the spirit and atmosphere advocated by positive leadership will better stimulate the organizational citizenship behavior of the members of the organization.

Another factor that can't be ignored is the social and cultural factors that employees are in. The scholars collected data from Japan, the United States and Hungary, and found that the social and cultural differences among countries are one of the reasons for the differences in the intrinsic motivation level of employees [22]. In the society with emphasis on collectivism culture, the motivation of employees is more due to the sense of duty to complete tasks than to choose actively, so the level of intrinsic motivation is low; In the society with emphasis on individualism culture, employees focus on themselves and consider personal interests more, so their intrinsic motivation level will be higher [23]. In the process of personal growth, social and cultural factors directly shape individual world outlook and values, and the differences of social moral standards will make people in different societies have different understanding of work ethics and achievements, and the spiritual needs pursued by each society are different. Social and cultural factors, it should be one of the key influencing factors for the level of individual intrinsic motivation in work. In the research of organizational behavior, cultural differences can lead to significant impact on individual behavior in organizations [24]. Therefore, based on the research of the effect of positive leadership on OCB, the paper will further explore the adjustment role of the differences in the cultural values (such as power distance) of employees.

Organizational leaders have the power to command and control subordinates because of organizational structure appointment, or personal professional skills and social status. The role of this power depends on subordinates' identification, awe, willingness and other factors. The intention is to measure the emotional distance between powerful leaders and subordinated employees [25]. Another scholar extends the concept to the field of social psychology, considers the concept of power distance at the social and cultural level, and defines it as the acceptance of the phenomenon of power equality in a society or system. This variable includes the relative 
relationship among parents, children, teachers and students, leaders subordinates and so on, which has been widely used in measuring the five factors of national culture. People think that in the society with high power distance, it is easier to accept the inequality of power distribution, and identify with and follow the instructions and orders of those who have power [24]. In the organizational context, Clugston extended the research variable of power distance to individuals, it also puts forward the concept of power distance tendency, which is used to measure the individual's acceptability to the uneven distribution of power in institutions or organizations [26]. Employees who are more loyal to their leaders are those who tend to have a greater power distance, accept the leadership style of the manager, obey and obey the authority of the leader, believe that the leader has the right to make any decision without consulting subordinates, and pay attention to the thoughts and feelings of the leader [27]. Studies have shown that individuals in the same culture also have different cultural values [28]. Then, in the Chinese context of the organization, how does the subordinate's cultural values affect the psychological influence of positive leadership on the organization members. The tendency of power distance is closely related to the cognition and interaction of subordinates to their leaders, and it also reflects the individual's values and basic beliefs about power [29]. Thus, considering the positive guiding role of positive leadership to subordinates, it may have an impact on the organizational citizenship behavior of employees.

\section{Theory and Hypotheses}

Self-determination theory is a kind of motivation process theory about human self-determination behavior; the theory claims that mankind are positive organisms with innate development potential and mentality growth. It is a free choice of action made by individuals on the basis of fully understanding environmental information and individual requirements. The potential of self-determination can guide people to commit themselves to behaviors that are of interest and conducive to ability development. This seek of self-determination constitutes the intrinsic motivation of mankind behavior [30]. Self-determination theory emphasizes the degree of mankind behavior, according to which motivation is regarded as a continuum. Its foundation is the organic dialectical meta theory, which claims that social environment can enhance human's intrinsic motivation, boost the internalization of external motivation and ensure human's healthy growth by supporting the satisfaction of three basic mental requirements of competence, autonomy and relationship.

Positive leadership includes optimism and "can do" mentality, altruism, moral orientation, motivation characteristics and other elements: optimism and "can do" mentality, positive leaders usually have a positive attitude and "can do" mentality [31], which means that leaders give members full freedom to play space, And it can make the members of the organization keep optimistic and hopeful confront difficulties [11]; Altruism, positive leaders are not only optimistic, but also able to make self-sacrifice, and usually put the needs of organizational members before their own needs. Such leaders (compared with leaders with self-interest) can more effectively motivate organizational team members to ensure the realization of organizational goals [32]. Motivation characteristics: positive leadership not only establishes positive goals, but also can motivate itself, and motivate team members [33]. Therefore, we propose the following hypotheses:

Hypothesis 1: positive leadership is positively related to intrinsic motivation.

Because intrinsic motivation is the factor that motivates individuals to complete tasks, employees with higher intrinsic motivation level will show higher enthusiasm in the work, and also affect their attitude and behavior in the work, such as work satisfaction, affectivity commitment and other variables, which will also affect the performance of employees in the work Organizational citizenship behavior plays a certain role. For employees with higher level of intrinsic motivation, they will also have higher satisfaction with work, and they can identify with the organization, establish emotional relationship with the organization, and the level of organizational commitment is also relatively high[34]. Furthermore, there is a remarkable positive correlation between intrinsic motivation and personal work performance. Compared with subordinates with lower intrinsic motivation level, subordinates with high intrinsic motivation will devote more energy and time to work, they are more willing to pay extra efforts and

ISSN: 0010-8189

(C) CONVERTER 2021

www.converter-magazine.info 
show more initiative behaviors in the organization, which will eventually be transformed into the improvement of performance level of employees in the work [35]. Similarly, intrinsic motivation can also predict the OCB of workers. Those who show more altruistic behavior in work are those with high motivation level and fulfill tasks outside of their job responsibilities[36].

Employees with high intrinsic motivation have good autonomy and initiative, which can not only encourage employees to devote themselves to work, but also actively seek some innovative methods to solve the problems encountered in work, and improve their task performance[37]. They are also likely to do things beyond their own responsibilities to meet their higher level of needs or to align their work behavior with their own values [38]. Although organizational citizenship behavior is not within the scope of employees' work responsibilities, nor within the scope of the company's compensation and reward system, it is an out of role behavior, but many scholars have found that the reason why employees show these behaviors is more likely to be due to their own internal reasons $[39,40]$. Based on this, the hypothesis is as below:

Hypothesis 2: intrinsic motivation mediates the relationship between positive leadership and organizational citizenship behavior.

The distance of power is first proposed from the perspective of social integrity, which is used to describe the values of power distance in a country or national society; the degree of uneven distribution of power refers to the power distance between the less powerful and the other with more power [25]. Then, the power distance is defined as the unequal distribution of power in an organization. The high power distance tends to think that the power difference between the upper and lower levels is legitimate and reasonable [41]. They are more likely to accept the suggestion and influence of leaders, and show more compliance to leaders [42], and are usually lack of autonomy and initiative. Instead, the subordinates with low power distance tendency consider the position between leaders and subordinates should be equal, they don't like the difference between the ranks, and hope to participate in the decision-making of the company [43]. In addition, the consistency of power distance between leaders and subordinates will have an impact on subordinates, and the value orientation of authorized leadership and low power distance is consistent [29]. Naturally, when active leaders involve subordinates in decision-making and let them decide to complete their work tasks, they will be overwhelmed by the employees with high power distance, because they are more accustomed to accepting the instructions of leaders and doing things according to the methods designated by leaders, and it is more unlikely that initiative ideas can be generated in their hearts. The subordinates with low power distance tendency think that the open and independent authorized leadership style is exactly what they need. Supportive and autonomous leadership can have a stronger positive impact on subordinates with low power distance [44]. High power distance people are willing to comply with the superior, recognize and accept the level and position differences between managers and employees, and prefer accept various orders from top to bottom in their work, and they will abide by the role norms of compliance, trust and maintenance of managers [45]. Therefore, we have reason to predict that positive leadership can meet the basic psychological needs of employees with low power distance. Based on this, we propose a hypothesis:

Hypothesis 3: the relationship between positive leadership and intrinsic motivation is moderated by power distance. Compared with employees with low power distance, positive leadership has a weaker positive impact on the intrinsic motivation of high power distance employees.

From hypothesis 2 and hypothesis 3, we can see that power distance plays a mediating role. That is to say, for employees with high power distance, positive leadership can affirm, encourage and trust subordinates' work, and give subordinates more recognition and greater autonomy in their work, which is in line with the social and cultural values of employees with low power distance, and can better stimulate subordinates' intrinsic motivation, so that they can make more out of role behaviors beneficial to the organization, That is organizational citizenship behavior. In contrast, employees with high power distance often do not need more autonomy, but want to get direct orders and instructions from leaders. Therefore, this kind of leadership with low power distance will make the employees with high power distance feel great pressure, so it is not easy to stimulate the subordinates' intrinsic 
motivation, which is obviously not conducive to the subordinates to show more extra efforts [46]. Based on this, we propose a hypothesis:

Hypothesis 4: positive leadership is moderated by power distance through the mediating effect of intrinsic motivation on OCB. Compared with high power distance, the indirect effect of intrinsic motivation with low power distance is stronger.

According to the above hypothesis, the research model of this study is shown in Figure 1 :

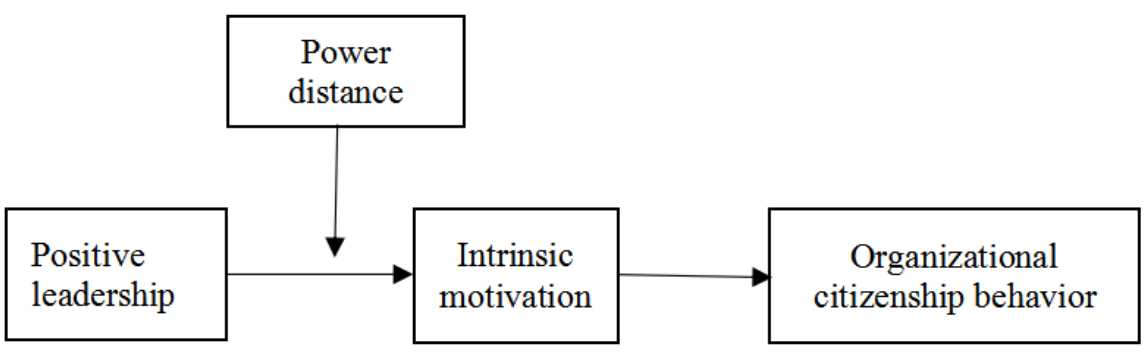

Fig 1: Hypothetical model

\section{Methods}

\subsection{Samples and procedures}

The sample selection of this study is mainly from different types of enterprises in many provinces and cities in China. Due to the serious epidemic of cowid-19 in the past two years, it is difficult to conduct face-to-face communication and offline research. Therefore, we communicate with some employees from the enterprise through the Internet and telephone to discuss the rationality of the scale items, and make minor changes to some statements. At the same time, we also use statistical analysis method to test the homologous variance, so as to ensure the validity of the data. This survey covers a wide range of areas and industries. In the description of the questionnaire, it is said that all the surveys are for academic research and strictly confidential. Please feel free to answer. The questionnaire survey was conducted online through a well-known app software in China. The researchers initially distributed a total of 330 questionnaires. After screening, 281 valid questionnaires were collected, with an effective rate of $85.15 \%$. Among all the subjects, $53.4 \%$ were male and $46.6 \%$ were female; According age, $71.2 \%$ of the respondents were between 25 and 45 years old; In terms of educational level, $48.0 \%$ of them had college education or above; In terms of working years, $61.5 \%$ of the employees who have worked for more than 3 years, which indicates that the respondents are relatively stable; The overall distribution of samples is reasonable.

\subsection{Measures}

The research process adopts standard scale tested by scholars. Most of the researches related to Chinese situation adopt Likert's 5-point scale, we used a five point Likert scale ranging from 1 ("strongly disagree") to 5 ("strongly agree").

\subsubsection{Positive leadership}

Positive leadership is a high-quality and positive behavior of leaders who pay attention to the positive emotions of the members of the organization. Although some progress has been made in the research of positive leadership, there are still no mature results on how to enter deeper research positive leadership [33]. There are two main popular scales of measurement dimensions of positive leadership, one is the one dimension structure scale [47], 
which contains four items, which has good reliability and validity. The other is the positive leadership scale developed by Chinese scholars, with a total of four dimensions, mainly including stimulating enthusiasm, sharing vision, setting an example and challenging stereotypes[48]. We mainly used the items of the scale of positive leadership developed by Chinese scholar Wang Tiandong (2020). The main items include: my leader pays attention to the development of positive relationship with team members, and my leader often praises the team members for their excellent completion of their work. After testing, the Cronbach's alpha coefficient of the positive leadership scale was 0.85 .

\subsubsection{Power distance}

We have found that many scholars usually regard power distance as a single dimension variable. Hofstede (1984) proposed a single dimension structure of power distance and constructed a corresponding measurement scale from the national level. There are three items in the scale, which are mainly used for the study of cultural differences. Dorfman and Howell (1988) introduced Hofstede research into the organizational and personal level, proposed the measurement of power distance at the individual degree, and compiled a total of 6 items of measurement scale, which has been tested by many researchers, and is one of the most commonly used scales. Earley and Erez (1987) designed the power distance scale at individual level, which has 8 items. After that, Farh et al. (2007) conducted research in the background of China, collected data, and compiled a single dimension power distance measurement scale for Chinese situations. The scale has 6 items in total, and its effectiveness has also been tested by empirical analysis. Based on the Farh (2007) scale, the main topics include: leaders do not need to ask their subordinates for advice in the decision-making process, and leaders must use their authority in the work. Through statistical analysis, the Cronbach's alpha coefficient of the power distance is 0.87 .

\subsubsection{Intrinsic motivation}

As for the measurement scale of intrinsic motivation, the most widely used one is the work preference scale developed by Amabile (1994). The intrinsic motivation subscale of the scale includes five components: self-determination, competence, work participation, curiosity and interest. The scale has a high reliability, with a total of 15 items. The intrinsic motivation proposed by Vallerand (1997) is also relatively mature, which can be divided into three aspects: the pleasure of work itself, the pleasure of achievement and the pleasure of learning. In addition, the intrinsic motivation scale developed by Tierney (1977) has a high reliability, which has five items. Chinese scholar Zhang Jian (2003) compiled the scale of employees' work motivation in Chinese context with reference to the work preference scale developed by Amabile. The intrinsic motivation subscale consists of three components, namely, the pursuit of competence, self-determination and good relationship. It has been verified that the scale has high validity and reliability. We use the work motivation scale developed by Gagne et al. (2010), in which there are three items of intrinsic motivation, such as: I like this job very much, this job can make me have a lot of fun. The Cronbach's alpha coefficient of intrinsic motivation is 0.87 .

\subsubsection{Organizational citizenship behavior}

For the measurement of OCB, different scholars have designed various types of scales based on different dimensions. Smith et al. (1983) developed a total of 16 items of measurement scale based on the two-dimensional cognition of organizational citizenship behavior through interviews, which is also the first developed scale of organizational citizenship behavior. Morgan (1988) continued in-depth research and divided its dimensions in more detail, and developed an organizational citizenship behavior measurement scale with 5 dimensions and 22 items in total. Latham and Skarlicki (1995) sorted out the organizational citizenship behavior observed by university teachers, and developed an OCB scale with 11 items based on the five dimensions division of organ. Farh et al. (2007) took the Chinese context as the research background, divided the organizational citizenship behavior into three dimensions: Pro socialist, voice behavior and conscientiousness, and developed the organizational citizenship behavior measurement scale suitable for China's local research. We used the scale of Farh (2007), which contains nine items, For example: I will take the initiative to give help to colleagues with heavy work tasks; if necessary, I will take the initiative to work overtime to complete the task. The Cronbach's alpha coefficient of OCB is 0.78 .

ISSN: 0010-8189 


\section{Results}

\subsection{Common method deviation test}

Because the scales in this study are all filled in by employees, and they are all carried out at one time point, generally, it is necessary to check whether there are common method deviations. In order to inspect whether the problem of common method deviation is serious. We use the Harmon single factor method to test. Through the factor analysis without rotation, multiple factors are separated out, and the eigenvalue of the first factor is 5.26, which can explain $22.86 \%$ of the variation, not accounting for half of the total variation (59.23\%). Therefore, it can be judged that the research results will only be affected by the small deviation of common methods, which does not hinder the accuracy of the research results.

\subsection{Descriptive statistics}

Table 1 lists the mean value, standard deviation, reliability and correlation coefficient of each variable used in this study. As we can see, there is a remarkable positive correlation between positive leadership and intrinsic motivation $(r=0.26, \mathrm{P}<0.001)$, between positive leadership and organizational citizenship behavior $(\mathrm{r}=0.27, \mathrm{P}<$ 0.001), and between intrinsic motivation and organizational citizenship behavior $(\mathrm{r}=0.25, \mathrm{P}<0.001)$. The results provide preliminary evidence for our hypothesis.

Table 1 Mean, standard deviations, and correlations among variables

\begin{tabular}{lllllllll}
\hline Vavriable & 1 & 2 & 3 & 4 & 5 & 6 & 7 & 8 \\
\hline 1.Gender & - & & & & & & & \\
2.Age & $-0.15^{*}$ & & & & & & & \\
3.Education & 0.04 & 0.04 & & & & & & \\
$\begin{array}{l}\text { 4.Tenure } \\
\text { 5.Positive leadership }\end{array}$ & -0.08 & $0.48^{* * *}$ & $0.32^{* * *}$ & & & & & \\
6.Power distance & -0.04 & -0.11 & 0.06 & -0.01 & $(0.85)$ & & & \\
7.Intrinsic motivation & -0.01 & $-0.12^{*}$ & -0.02 & -0.04 & 0.08 & $(0.87)$ & & \\
$\begin{array}{l}\text { 8.Organizational } \\
\text { citizenship }\end{array}$ & 0.01 & 0.01 & $0.21^{* * *}$ & -0.03 & $0.26^{* * *}$ & -0.04 & $(0.87)$ & \\
$\quad$ & 0.05 & 0.02 & $0.25^{* *}$ & $0.17^{* *}$ & $0.27^{* * *}$ & -0.09 & $0.25^{* * *}$ & $(0.78)$ \\
$\begin{array}{l}\text { Meanavior } \\
\text { Standard deviations }\end{array}$ & & & & & & & & \\
\hline
\end{tabular}

$N=281 ; * p<0.05 ; * * p<0.01 ; * * * p<0.001$ (Two-tailed)

\subsection{Confirmatory factor analysis}

Similar to most researches in organizational behavior, confirmatory factor analysis is used to judge the matching between the collected data and the measurement model. For the sake of test the validity of judgment, we compared the four factors hypothesis model with four alternative models, and compared other models with their fitting indexes. Results as shown in Table 2, the goodness of fit of the four factor model was better $(\chi 2=397.71, d f=224$, $\mathrm{CFI}=0.92$, TLI $=0.91, \mathrm{SRMR}=0.06, \mathrm{RMSEA}=0.05$ ). The results also show that positive leadership, power distance, intrinsic motivation and organizational citizenship behavior can represent different constructs and have strong discriminative validity.

ISSN: 0010-8189 
Table 2 Results of confirmatory factor analysis

\begin{tabular}{lcccccl}
\hline Models & $\chi 2$ & $d f$ & CFI & TLI & SRMR & RMSEA \\
\hline $\begin{array}{l}\text { A four-factor model } \\
\text { A first three-factor }\end{array}$ & 807.71 & 224 & 0.92 & 0.91 & 0.06 & 0.05 \\
model & & 227 & 0.74 & 0.72 & 0.09 & 0.10 \\
$\begin{array}{l}\text { A second three-factor } \\
\text { model }\end{array}$ & 830.40 & 227 & 0.73 & 0.70 & 0.11 & 0.10 \\
A two-factor model & 1176.09 & 229 & 0.58 & 0.53 & 0.11 & 0.12 \\
A one factor model & 1556.44 & 230 & 0.41 & 0.35 & 0.13 & 0.14 \\
\hline
\end{tabular}

PL: positive leadership; PD: power distance; IM: intrinsic motivation; OCB: organizational citizenship behavior A four-factor model: PL; PD; IM; OCB.

A first three-factor model: PL and PD; IM; OCB.

A second three-factor model: PL; PD and IM; OCB.

A two-factor model: PL 、 PD and IM; OCB.

A one factor model: PL、 PD、 IM、 OCB.

\subsection{Hypothesis testing}

Hypothesis 1 proposes that positive leadership can positively affect intrinsic motivation, and it can conduct the influence of positive leadership, and then indirectly affect organizational citizenship behavior (Hypothesis 2). According to Baron \& Kenny (1986). Firstly, we regress organizational citizenship behavior to positive leadership, such as model 5 of Table 3 , and we can find that the regression coefficient reaches a significant level $(\beta=0.26, p<$ 0.001 ) .Then intrinsic motivation regressed to positive leadership, such as model 2 in Table 3, and the regression coefficient was significant $(\beta=0.26, \mathrm{P}<0.001)$, which proves hypothesis 1 . We add intrinsic motivation to model 5 and get Model 6. Intrinsic motivation has a remarkable positive effect on $\mathrm{OCB}(\beta=0.17, \mathrm{P}<0.01)$ and the regression coefficient of positive leadership decreased from 0.26 to 0.22 , but it was still significant. It shows that intrinsic motivation plays a partial mediating role, and hypothesis 2 is proved.

Hypothesis 3 proposes that employee's power distance can weaken the positive influence of positive leadership on intrinsic motivation. That is to say, compared with employees with high power distance, positive leadership has a stronger positive influence on employees with low power distance. Results as shown in Table 3, on the basis of adding independent variables to the model (model 3), adding modertor and interaction items in turn (model 4), the regression coefficient of interaction items was significantly higher $(\beta=0.25, \mathrm{P}<0.001)$. Explain that hypothesis 3 is proved.

Table 3 Results of polynomial regression

\begin{tabular}{|c|c|c|c|c|c|c|}
\hline \multirow[t]{2}{*}{ Variable } & \multicolumn{3}{|c|}{ Intrinsic motivation } & \multicolumn{3}{|c|}{ Organizational citizenship behavior } \\
\hline & Model 1 & Model 2 & Model 3 & Model 4 & Model 5 & Model 6 \\
\hline \multicolumn{7}{|l|}{$\overline{\mathbf{C V}}$} \\
\hline Gender & -0.03 & -0.01 & -0.02 & -0.02 & 0.07 & 0.07 \\
\hline Age & 0.05 & 0.08 & -0.02 & 0.09 & -0.00 & -0.02 \\
\hline Education & 0.26 & 0.24 & 0.07 & $0.20 * *$ & $0.19 * *$ & $0.15^{*}$ \\
\hline Tenure & -0.14 & $-0.15^{*}$ & $-0.24 * * *$ & $-0.14 *$ & 0.12 & $0.14 *$ \\
\hline \multicolumn{7}{|l|}{ IV } \\
\hline Positive leadership & & $0.26 * * *$ & $0.25 * * *$ & $0.23 * * *$ & $0.26 * * *$ & $0.22 * * *$ \\
\hline \multicolumn{7}{|l|}{ Moderator } \\
\hline Power distance & & & -0.05 & -0.06 & & \\
\hline
\end{tabular}

ISSN: 0010-8189 
INT

$\mathrm{PL} * \mathrm{PD}$

\section{Mediator}

Intrinsic motivation

$\mathrm{R}^{2}$

$\Delta \mathrm{R}^{2}$

$$
-0.25 * * *
$$

$\begin{array}{llllll}0.06 & & & & 0.17 * * \\ & 0.12 & 0.12 & 0.18 & 0.14 & 0.17 \\ & 0.06^{* * *} & 0.00 & 0.06^{* * *} & 0.06^{* * *} & 0.03^{* *}\end{array}$

In addition, we make a simple slope analysis and draw a moderate effect diagram to show the moderate effect of power distance more intuitively. According to the suggestion of Aiken \& West (1991), we first average the independent variables and moderate variables to prevent collinearity, and then calculate the interaction terms according to the average results, and then carry out regression analysis. Finally, draw the graph according to the regression coefficient. As shown in Figure 2, when employees' power distance is high, the influence of positive leadership on employees' intrinsic motivation is positive, but not significant (simple slope $=0.06, \mathrm{P}<0.05$ ). Instead, when employees' power distance is low, positive leadership can have a remarkable positive influence on employees' intrinsic motivation (simple slope $=0.56, \mathrm{P}<0.001$ ). And the difference of simple slope in the two situations reached a significant level (difference $=0.5, \mathrm{P}<0.05$ ). This further proves the validity of hypothesis 3 .

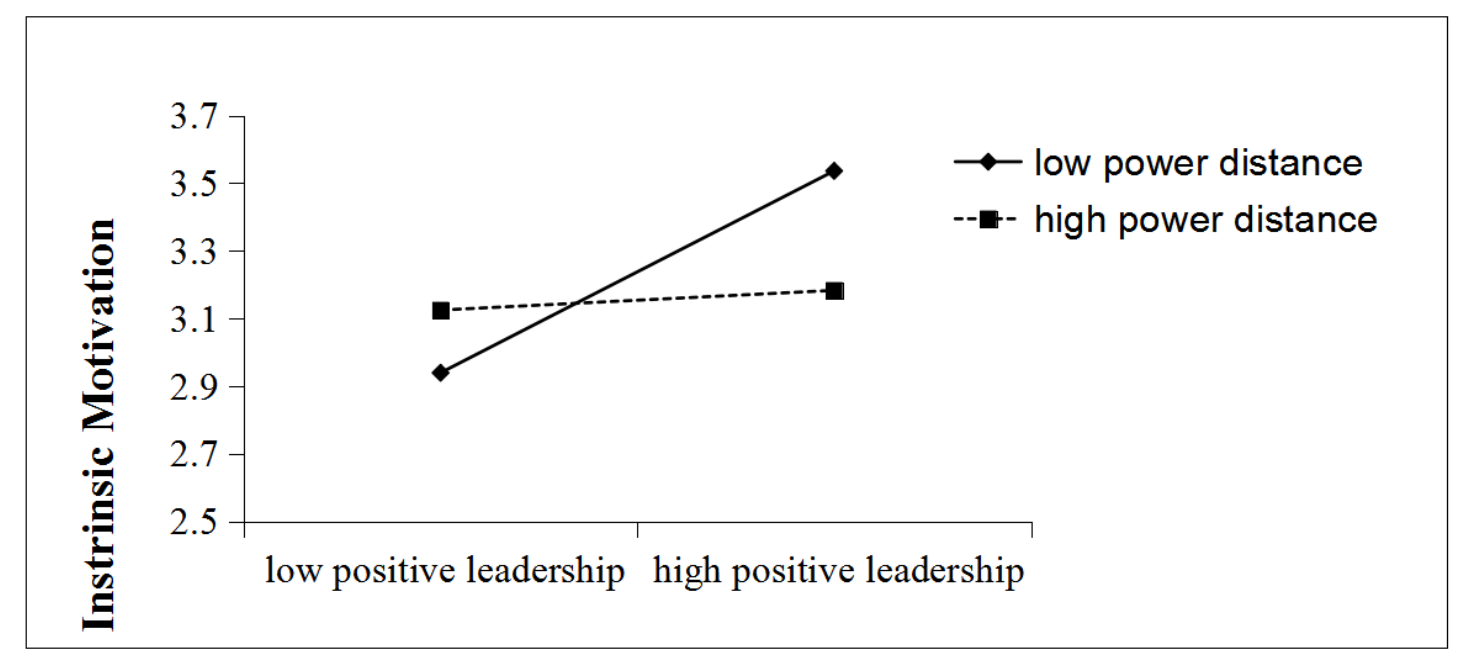

Fig 2: The moderating effect of power distance on the relationship between positive leadership and intrinsic motivation

Hypothesis 4 proposes that the power distance of employees can weaken the mediating effect of intrinsic motivation, that is, compared with the employees with high power distance, positive leadership can influence the intrinsic motivation of employees with low power distance more, so as to promote employees to show more organizational citizenship behavior. Table 4 shows that for workers with low power distance, positive leadership can produce significant indirect effect on OCB through intrinsic motivation (indirect effect $=0.05,95 \% \mathrm{CI}=[0.009$, 0.117]). However, for employees with high power distance, the indirect effect was not remarkable (indirect effect $=$ $0.01,95 \% \mathrm{CI}=[-0.028,0.055])$. In addition, in two different scenarios, the difference of indirect effect reached a significant level (difference $=0.05,95 \% \mathrm{CI}=[-0.136,-0.002]$ ). This result shows that hypothesis 4 is proved by data. 
Table 4 The test of moderated mediators

\begin{tabular}{|c|c|c|c|c|}
\hline \multirow{4}{*}{ Moderator } & \multicolumn{2}{|c|}{ Positive leadership $(\mathrm{X})$} & \multicolumn{2}{|c|}{ Intrinsic motivation $(\mathrm{M}) \longrightarrow$} \\
\hline & $\mathrm{OCB}(\mathrm{Y})$ & & & $95 \% \mathrm{CI}$ \\
\hline & Procedure & & Effect & \\
\hline & First $\left(\mathrm{P}_{\mathrm{MX}}\right)$ & $\operatorname{Second}\left(\mathrm{P}_{\mathrm{YM}}\right)$ & Indirect effect & \\
\hline High power distance & 0.06 & $0.09 *$ & 0.01 & {$[-0.028,0.055]$} \\
\hline Low power distance & $0.56 * * *$ & $0.09 *$ & 0.05 & {$[0.009,0.117]$} \\
\hline Difference & $-0.51 *$ & $0.09 *$ & -0.05 & {$[-0.136,-0.002]$} \\
\hline
\end{tabular}

\section{Discussion}

The moderated mediation model was supported. We find that positive leadership is positively related to intrinsic motivation, conversely, positive leadership is positively related to organizational citizenship behavior. The low power distance improves the impact of positive leadership on intrinsic motivation, and indirectly improves the impact of positive leadership on OCB through intrinsic motivation. Therefore, our research is not only helpful to the literature research of positive leadership and organizational citizenship behavior, but also has important guiding significance for the practice of enterprise management.

\subsection{Theoretical contributions}

The results of this study show that: positive leadership can arouse the intrinsic motivation of workers, therefore promoting employees to show more organizational citizenship behavior, and the effectiveness of positive leadership will be affected by the cultural values of the power distance of employees. Specifically, the power distance of employees can weaken the positive role of positive leadership on employees' intrinsic motivation, It can also influence the indirect influence of OCB through intrinsic motivation.

The research on positive leadership has not been too many in recent years. The above results are helpful to understand the specific mechanism and effective boundary of positive leadership. The above results are helpful to understand the specific mechanism and effective boundary of leadership In terms of the mechanism of action, this study first uses intrinsic motivation to explain how positive leadership has an impact on the behavior outside the role of subordinates. Previous studies are based on the perspective of social exchange [49]. It is pointed out that positive leaders believe that employees can complete their work tasks, and at the same time, they will realize the importance of team, these can improve the key factors of employees' trust and support to leaders, and improve the quality of exchange relationship between them. Based on the principle of reciprocity, employees will pay more efforts to repay leaders, and OCB is one of the important forms of expression. Of course, the external environment is not the only factor that affects the employees' behavior response. Even in the supportive environment, employees may not take the initiative to take part in out of role behavior [50]. Besides the environment, self-awareness and self-determination are also an important factor in determining individual response. From this perspective, this research, based on the theory of self-determination, chooses a new perspective of intrinsic motivation to open up the process of positive leadership in the behavior outside the role of employees, which can not only help people understand the mechanism of positive leadership, At the same time, it expands the application scope and field of self-determination theory.

The boundary problem of leadership effectiveness has always been the focus of management academia. In the past, when exploring the effectiveness of positive leadership, many scholars will choose the relevant factors related to their subordinates [51]. However, it is seldom considered whether the values embodied in leadership style itself match the values of subordinates. This paper fills in this gap, and verifies the importance of consistency between leadership style and subordinate cultural values, indicating that the impact on the work results of employees is the matching between leadership style and subordinate style, not one of them. At the same time, the results of this

ISSN: 0010-8189

(C) CONVERTER 2021 
study also support Farh et al. (2007) and Kirkman et al. (2009). That is, leadership style based on Western culture often has a negative impact on employees with high power distance.

\subsection{Practical contributions}

The conclusion of this study also has a certain practical significance to guide the practice of enterprise management.

First of all, the research results show that positive leadership can improve the intrinsic motivation of employees, which indicates that enterprises should give more care and encouragement to employees, and leaders should give more care and encouragement, which can improve the enthusiasm and initiative of front-line employees, and help them take effective measures quickly when facing emergency, Instead of waiting for instructions from company leaders, they can voluntarily participate in more things that help company colleagues and strengthen the organization.

Secondly, the study claims that positive leadership can have a more positive impact on employees with low power distance. Therefore, when leaders hearten workers to participate in decision-making and improve their autonomy, they should also vary from person to person. According to the individual differences of employees, they should take measures that match their cultural values, so as to better play the effectiveness of leadership and management, In particular, China has a typical culture of high power distance, and positive leadership requires leaders to lower their attitude, communicate more with employees, and better stimulate their work enthusiasm and initiative.

\subsection{Limitations and future directions}

Although some achievements have been made in this study, there are still some limitations in our studies, which provides a possible way for future research.

First of all, the first limitation mainly comes from the data. Due to the impact of the covind-19 epidemic, it is impossible to communicate with the relevant personnel of the enterprise face to face, and the questionnaire survey is divided into different time points to measure, so that the accuracy of the data will be higher. Moreover, the number of samples from different industries and regions is not enough, and the selected samples may affect the external validity of the conclusion. Moreover, the samples we have adopted are limited to Chinese mainland, though they have important enlightenment to Chinese mainland's management practices. However, we suggest that in the future research, we can focus on a certain industry, or use a larger sample in more different types of enterprises or countries to test our research hypotheses.

Secondly, the influence of positive leadership on OCB is still in its infancy. This study mainly studies the indirect impact of positive leadership on OCB through intrinsic motivation. Whether there are many more alternative mechanisms. It is also hoped to be developed and studied in the future research.

Finally, the non-experimental nature of our research prevents us from making strong causal inferences. Although we have conducted a detailed investigation and analysis, and made a lot of communication with relevant personnel of the enterprise, to a certain extent, we may eliminate some fuzziness about the direction of causality. However, it is still a cross-sectional study in essence, and some longitudinal study designs may be added in future studies to better capture the causal relationship between these variables.

\section{Conclusion}

This study links positive leadership with employee behavior, and explores the mediating role of employees' intrinsic motivation and the moderating role of power distance between positive leadership and OCB. The research also adds a new explanation for the research of leadership, that is, the new explanation of the influence of positive leadership on worker behavior and attitude, which provides a new research reference direction on positive

ISSN: 0010-8189

(C) CONVERTER 2021 
leadership, and provides important enlightenment for practitioners.

\section{References}

[1] Organ, D. W. Organizational citizenship behavior: The good soldier syndrome. Lexington Books/D. C. Heath and Com, 1988.

[2] Li Chaoping, Tian Bao, Shi Kan. Transformational leadership and employee work attitude: the intermediary role of psychological empowerment. Journal of psychology, 38 (2): 297-307, 2006.

[3] Arnold, J.A. Arad, S. Rhoades, J.A. et al., "The empowering leadership questionnaire: the construction and validation of a new scale for measuring leader behaviors," Journal of Organizational Behavior, vol. 21, no. 3, pp. 249-269, 2000.

[4] Zhang, X., \& Bartol, K. M. Linking empowering leadership and employee creativity: The influence of psychological empowerment, intrinsic motivation, and creative process engagement. Academy of Management Journal, 53(1): 107-128, 2010.

[5] Srivastava, A., Bartol, K.M., \& Locke, E. A. Empowering leadership in management teams: Effects on knowledge sharing, efficacy, and performance. Academy of Management Journal, 49(6): 1239-1251, 2006.

[6] A. Carmeli, J. Schaubroeck, A. Tishler, "How CEO empowering leadership shapes top management team processes: Implications for firm performance,” Leadership Quarterly, vol. 22, no. 2, pp. 399-411, 2011.

[7] Blanch, Javier; Gil, Francisco; Antino, Mirko; Rodríguez-Muñoz, Alfredo MODELOS DE LIDERAZGO POSITIVO: MARCO TEÓRICO Y LÍNEAS DE INVESTIGACIÓN Papeles del Psicólogo, vol. 37, núm. 3, septiembre, pp. 170-176, 2016

[8] Härtel, Charmine E. J., et al. "Work-Group Emotional Climate, Emotion Management Skills, and Service Attitudes and Performance.” Asia Pacific Journal of Human Resources, vol. 46, no. 1, pp. 21-37, 2008 .

[9] yubomirsky, S., King, L., \& Diener, E. The Benefits of Frequent Positive Affect: Does Happiness Lead to Success? Psychological Bulletin, 131(6), 803-855,2005.

[10] Cameron K, Mora C, Leutscher T, Calarco M. Effects of Positive Practices on Organizational Effectiveness. The Journal of Applied Behavioral Science. 47(3):266-308. 2011.

[11] D. Arakawa, M. Greenberg, Optimistic managers and their influence on productivity and employee engagement in a technology organisation: Implications for coaching psychologists, International Coaching Psychology Review, Volume 2 ,PP78-80,2007.

[12] Lee, A., Willis, S., \& Tian, A. W. Empowering leadership: A meta- analytic examination of incremental contribution, mediation, and moderation. Journal of Organizational Behavior, 36(3): 306-325.2018.

[13] Zhang Huijuan, Hu Junchen, Guo Li. The influence of empowering leadership on employees' organizational citizenship behavior. China Statistics, 437 (5): 57-59, 2018.

[14] SD Gladis, M Goldsmith ,Positive leadership: The game changer at work, Books/D. C. 2013

[15] Bernard M.Bass, Two Decades of Research and Development in Transformational Leadership, European Journal of Work and Organizational Psychology, Volume 8, Pages 9-32, 1999.

[16] J. Felfe, B. Schyns. Personality and the Perception of Transformational Leadership: The Impact of Extraversion, Neuroticism, Personal Need for Structure, and Occupational Self-Efficacy. Journal of applied social psychology, 36(3): 708-739, 2006.

[17] Peter G. Northouse, Leadership: Theory And Practice,books , 16th,2018

[18] Adrian Furnham, Liam Forde, Kirsti Ferrari,Personality and work motivation,Personality and Individual Differences, Volume 26, Issue 6,Pages 1035-1043,1999

[19] Deci, E. L., \& Ryan, R. M. Intrinsic motivation and self-determination in human behavior. New York: Plemun Press, 1985.

[20] Deci, E. L., Connell, J. P., \& Ryan, R. M. Self-determination in a work organization. Journal of Applied Psychology, 74(4), 580-590,1989. 
[21] Marylène Gagné, Edward L. Deci, Self-determination theory and work motivation, Journal of organizational behavior, Volume26, Pages 331-362,2005

[22] Peterson MF, Ruiz-Quintanilla SA. Cultural Socialization as a Source of Intrinsic Work Motivation. Group \& Organization Management.28(2):188-216,2003.

[23] Iyengar, S. S., \& DeVoe, S. E. (2003). Rethinking the value of choice: Considering cultural mediators of intrinsic motivation. In V. Murphy-Berman \& J. J. Berman (Eds.), Cross-cultural differences in perspectives on the self (pp. 146-191). University of Nebraska Press.

[24] Geert Hofstede, Culture and Organizations, International Studies of Management \& Organization, Volume 10, Pages 15-41,1980

[25] Sik-Hung Ng, Structural and nonstructural aspects of power distance reduction tendencies, European journal of social psychology, Volume7, Pages 317-345,1977

[26] Clugston M, Howell JP, Dorfman PW. Does Cultural Socialization Predict Multiple Bases and Foci of Commitment? Journal of Management. 26(1):5-30, 2000.

[27] Bochner S, Hesketh B. Power Distance, Individualism/Collectivism, and Job-Related Attitudes in a Culturally Diverse Work Group. Journal of Cross-Cultural Psychology. 25(2):233-257,1994.

[28] Lian, H., Ferris, D. L., \& Brown, D. J. Does power distance exacerbate or mitigate the effects of abusive supervision? It depends on the outcome. Journal of Applied Psychology, 97(1): 107-123, 2012.

[29] Cole, M. S., Carter, M. Z., \& Zhang, Z. Leader-team congruence in power distance values and team effectiveness: The mediating role of procedural justice climate. Journal of Applied Psychology, 98(6): 962-973, 2013.

[30] Edward L.DeciRichard M.Ryan, The general causality orientations scale: Self-determination in personality, Journal of Research in Personality, Volume 19, , Pages 109-134,1985.

[31] Malinga K.S., Stander M., Nell W. Positive Leadership: Moving Towards an Integrated Definition and Interventions. Theoretical Approaches to Multi-Cultural Positive Psychological Interventions. VOLUME 3, pp 201-228,2019

[32] David DeCremerDaan vanKnippenberg, Leader self-sacrifice and leadership effectiveness: The moderating role of leader self-confidence, Organizational Behavior and Human Decision Processes, Volume 95, Pages 140-155, 2004.

[33] Mirko Antino, Francisco Gil-Rodríguez, Alfredo Rodríguez-Muñoz \&Stefano Borzillo, Evaluating positive leadership: pilot study on the psychometric properties of a reduced version of the Positive Leadership Assessment Scale , International Journal of Social Psychology , VOLUME 29, pp 589-608, 2014.

[34] Lillian T. Eby, Deena M. Freeman, Michael C. Rush, Charles E. Lance, Motivational bases of affective organizational commitment: A partial test of an integrative theoretical model, Journal of Occupational and Organizational Psychology, Volume 72, PP 463-483, 1999.

[35] Anders Dysvik, Bård Kuvaas , Intrinsic and extrinsic motivation as predictors of work effort: The moderating role of achievement goals, British Journal of Social Psychology, Volume 52, pp 412-430,2013.

[36] Mark C. Bolino, Citizenship and Impression Management: Good Soldiers or Good Actors? , Academy of Management ReviewVol. 24, No. $1,1999$.

[37] Amabile,T. M.. The Social Psychology of Creativity. New York: Spingerr-Verlag, 1983.

[38] Duan Jinyun, Huang Caiyun. The influence mechanism of transformational leadership on employee voice: a self-determination perspective. Nankai management review, 17 (4): 98-109, 2014.

[39] Lee, K., \& Allen, N. J. Organizational citizenship behavior and workplace deviance: The role of affect and cognitions. Journal of Applied Psychology, 2002, 87: 131-142.

[40] Rioux, S. M., \& Penner, L. A. The causes of organizational citizenship behavior: A motivational analysis. Journal of Applied Psychology, 86: 1306-1,2001.

[41] Tyler, T. R., Lind, E. A., \& Huo, Y. J. Cultural values and authority relations: The psychology of conflict resolution across cultures. Psychology, Public Policy, and Law, 6(4): 1138-1163.2000.

[42] Li, Y., \& Sun, J. M. Traditional Chinese leadership and employee voice behavior: A cross-level 
examination. The Leadership Quarterly, 26(2): 172-189, 2015.

[43] Atwater, L. E., Wang, M., Smither, J. W., Fleenor, J. W. Are cultural characteristics associated with a relationship between self and others` ratings of leadership? Journal of Applied Psychology, 2009, 94(4): 876-886.

[44] Duan Jinyun, Huang Caiyun. The influence mechanism of transformational leadership on employee voice: a self-determination perspective. Nankai management review, 17 (4): 98-109,2014.

[45] Sun Jianmin, song Meng, Wang Zhenren, The impact of abuse management on subordinates' job performance and turnover intention: the role of leadership identity and power distance, Business economy and management, No. 3, pp. 45-53, 2013

[46] Vansteenkiste, M., Simons, J., Lens, W., Sheldon, K. M., Deci, E. L. Motivating Learning, Performance, and Persistence: The Synergistic Role of Intrinsic Goals and Autonomy-support Contexts. Journal of Personality and Social Psychology, 87(2): 246-260.2004.

[47] Kelloway EK, Weigand H, McKee MC, Das H. Positive Leadership and Employee Well-Being. Journal of Leadership \& Organizational Studies. 20(1):107-117,2013.

[48] Yan Yanling, Zhang Junwei, Zhang Hong, research on the relationship between active leadership and employee engagement: from the perspective of self-determination, scientific research management, No. 6, pp. 257-267, 2019

[49] Zhang Huijuan, Hu Junchen, Guo Li. The influence of empowering leadership on employees' organizational citizenship behavior. China Statistics, 2018, 437 (5): 57-59

[50] J.R. Detert, A.C. Edmondson, "Implicit voice theories: taken-for-granted rules of self-censorship at work," Academy of Management Journal, vol. 54, no. 3, pp.461-488, 1988.

[51] Chen Chen, Qin Xin, Tan Ling, Lu hailing, Zhou Hansen, song bodi. The influence of empowering leadership subordinate Self Leadership matching on subordinate emotional exhaustion and job performance. Management world, 2020, 36 (12): 179-196. 